\title{
THERĪGĀTHĀ, A PRIMEIRA LITERATURA FEMININA NO BUDISMO: POSSIBILIDADES DE DIÁLOGO COM O EROTISMO NA TEOPOÉTICA
}

\author{
Nirvana de Oliveira Moraes Galvão de França* \\ Tattiane Yu Borges Marques**
}

\section{RESUMO}

O Therīgāthā é uma antologia de poemas escritos por mulheres sobre mulheres budistas, sendo o primeiro texto desta categoria no mundo. O eu-lírico destes poemas é a expressão da própria vivência, mulheres que eram mães, esposas, concubinas, prostitutas, viúvas... que transbordaram nos versos suas epifanias de despertar, mostrando o caminho trilhado, a razão da renúncia à vida em sociedade para se tornarem monjas budistas, celibatárias, em busca do mais elevado fruto do caminho, a paz definitiva. A trajetória de investigação destes versos inicia-se com uma apresentação do texto, sobre quem eram as anciãs que representavam as vozes das primeiras monjas na literatura budista, segue-se com uma análise do eu-lírico na experiência feminina, posteriormente sobre a possibilidade de teopoética desta antologia, em diálogo com o erotismo dos corpos na dissolução relativa com a sexualidade de Georges Bataille na obra "O Erotismo". Para que isso fosse possível, investigamos alguns versos, traduzidos do páli para o inglês por Charles Hallisey e, para as análises, efetuamos

* Doutoranda em Ciências da Religião junto à Universidade Metodista de São Paulo e graduanda em Teologia junto à Universidade Metodista de São Paulo. Bacharel em direito pela Universidade Liceu - unisal e possui formação em Teologia Budista pelo Instituto Pramāṇa (2018). Membra do Grupo de Pesquisa de Gênero e Religião Mandrágora. Possui formação em Teologia Budista pelo Instituto Pramāṇa (2018). Atua no programa de pós-graduação em Teologia Budista junto ao Instituto Pramāṇa.

** Mestranda em Ciências da Religião junto à Universidade Metodista de São Paulo e graduanda em Teologia junto à Universidade Cristã Dom Bosco. Membra do Grupo de Pesquisa de Gênero e Religião Mandrágora. Bacharel em Administração pelo Instituto Paulista de Ensino e Pesquisa (2004). Possui formação em Teologia Budista pelo Instituto Pramāṇa (2018). Atua no programa de pós-graduação em Teologia Budista junto ao Instituto Pramāṇa. 
uma pesquisa bibliográfica. A interpretação dos versos é uma interpretação livre, mas que ilustra o que esta obra nos traz em termos de possibilidades interpretativas da teologia budista.

Palavras-chave: Therīgāthā; budismo; literatura; feminino; teopoética.

\section{THERĪGĀTHĀ, THE FIRST FEMALE LITERATURE IN BUDDHISM: POSSIBILITIES OF DIALOGUE WITH EROTICISM IN THE THEOLOGY}

\section{ABSTRACT}

Therigäthā is an anthology of poems written by women about buddhist women and is the first text in this category in the world. The lyrical itself of these poems is the expression of their own experience, women who were mothers, wives, concubines, prostitutes, widows... who overflowed in the verses their awakening epiphanies, showing the trodden path, the reason for renouncing life in society to become celibate buddhist nuns, in search of the highest fruit of the path, ultimate peace. The investigation trajectory of these verses begins with a presentation of the text, about who were the elderly women who represented the voices of the first nuns in Buddhist literature, followed by an analysis of the lyrical itself in the female experience, later on the possibility of theopoetics of this anthology, in dialogue with the eroticism of bodies in the relative dissolution with the sexuality of Georges Bataille's "The Eroticism". For this to be possible, we investigated some verses, translated from páli to English by Charles Hallisey, and, for the analyses, we carried out a bibliographical research. The interpretation of the verses is a free interpretation, but it illustrates what this work brings us in terms of the interpretative possibilities of Buddhist theology.

Keywords: Therīgāthā; Buddhism; Literature; Feminine; theopoetics.

\section{THERĪGĀTHĀ, LA PRIMERA LITERATURA FEMENINA EN EL BUDISMO: POSIBILIDADES DE DIÁLOGO CON EL EROTISMO EN LA TEOLOGÍA}

\section{RESUMEN}

Therīgāthā es una antología de poemas escritos por mujeres sobre mujeres budistas, y es el primer texto de esta categoría en el mundo. El yo lírico de estos poemas es una expresión de su propia experien- 
cia, mujeres que fueron madres, esposas, concubinas, prostitutas, viudas... que desbordaron en los versos sus epifanías de despertar, enseñando el camino recorrido, la causa de renunciar a la vida en sociedad para convertirse en monjas budistas célibes, en busca del fruto más elevado del camino, la paz suprema. La trayectoria de investigación de estos versos empieza con una presentación del texto, sobre quiénes fueron los ancianos que representaron las voces de las primeras monjas en la literatura budista, seguido de un análisis del yo lírico en la experiencia femenina, posteriormente sobre la posibilidad de Teopoética de esta antología, en diálogo con el erotismo de los cuerpos en la relativa disolución con la sexualidad de Georges Bataille en la obra "O Erotismo". Para que esto sea posible, investigamos algunos versos, traducidos del páli al inglés por Charles Hallisey, y para los análisis realizamos una búsqueda bibliográfica. La interpretación de los versos es una interpretación libre, pero ilustra lo que nos aporta este trabajo en términos de las posibilidades interpretativas de la teología budista.

Palabras clave: Therīgāthā; budismo; literatura; feminino; teopoética.

\section{INTRODUÇÃO}

O Therīgāthā é uma antologia de literatura feminina na Índia. Escrita em Páli 80 a.C., foi composto pelas primeiras mulheres budistas durante a vida do Buda histórico ${ }^{1}$ no séc. V a.C na Índia. A coleção contém versos de monjas budistas que detalham desde o desencanto com os papeis que lhes são prescritos na sociedade até as suas lutas no caminho da iluminação. Entre as monjas, estão representadas várias vozes, incluindo ex-esposas, mulheres que perderam filhos, mulheres que abandonaram suas riquezas e uma ex-prostituta. Elas eram chamadas de therīs - mulheres iluminadas. Gāthā se refere a poemas. Dhammapala, um comentador budista sobre o Therīgāthā do século XVI, chama os poemas das therīs de udānas, que é uma forma de escritura budista canônica, associando o Therīgāthā com a escritura dos sermões do Buda. (Charles Hallisey, 2015).

Buddha Śákayanuni ou Buda Gautama que viveu por volta do séc. V a.C na Índia. Trata-se de uma Índia que não corresponde ao território dos dias atuais, pois incluía também o Nepal e outras áreas, que hoje são considerados como países independentes, na região do Himalaia (Plínio TSAI, 2019, p.21) 
Therīgāthã e Theragāthã são coleções de versos compilados em poemas atribuídos aos primeiros seguidores de Buda, feminino e masculino, respectivamente. Ambas as coleções são organizadas pelo número crescente de versos por poema, do menor para o maior. $\mathrm{O}$ Therīgāthā é, portanto, uma coleção de quinhentos e vinte e dois versos compilados em setenta e três poemas ${ }^{2}$ (Kathryn BLACKSTONE, 2000, p. 3, tradução nossa).

As vozes das mulheres em textos tão antigos são importantes até nos dias de hoje, pois há uma escassez de literatura budista feminina. $\mathrm{Na}$ atualidade os mais importantes professores são homens, são eles que se destacam no mais alto grau de hierarquia no budismo, enquanto as mulheres possuem pouca representatividade. Segundo Rita Gross (2011), essa é uma condição desigual, pois em termos quantitativos, a maioria das praticantes são mulheres e há poucas professoras mulheres, apesar de termos o Therīgātha como uma literatura religiosa tão antiga.

Rita Gross (1993) nos diz que, apesar da prática de manter registros androcêntricos, o Budismo indiano preservou um documento que registrou a vida nos tempos mais antigos das mulheres. Este documento é, sem dúvida, o Therīgāthā. Estes poemas se fazem voz para as mulheres budistas, não só por seu rico conteúdo de ensinamentos por meio de uma experiência poética, mas também por servir de inspiração ao trazer as vivências das mulheres em relação ao corpo, à sexualidade e beleza que as levaram à prática no sentido soteriológico do budismo: a busca da libertação dos sofrimentos, a paz definitiva.

Como é o método proposto pelo Buda e que leva à paz definitiva? Como vemos, há uma proposta soteriológica, no sentido de soteria

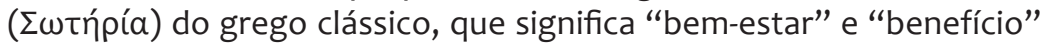
(LAMPE, 1961, p. 1369), no caso budista, considerados em seu estado mais elevado, último, e que equivale à cessação definitiva de todos os sofrimentos. O método fundamenta-se no conhecimento e na prática de fatores (dharma) que compõem a realidade. Assim, há uma on-

The Therīgāthā and Theragāthā are collections of verses compiled into poem's ascribed to the earliest followers of the Buddha, female and male, respectively. Both collections are arranged by ascending number of verses per poem, from shortest to longest. The Therigāthāis thus a collection of five hundred twenty-two verses compiled into seventy-three poems. 
tologia soteriológica (ou uma soteriologia ontológica), uma vez que se acredita firmemente que pelo conhecimento de como as coisas realmente são, a pessoa tem o poder de desenvolver em si mesma, e somente nela mesma, o estado da libertação pela paz definitiva de maneira irreversível (Plínio TSAI, 2021, p. 43, grifo no original).

Desta forma, esta exposição é dividida em três partes: a primeira é uma breve descrição de quem eram as anciãs que representavam as vozes das primeiras monjas na literatura budista. A segunda parte é sobre experiência poética, o eu-lírico na experiência feminina que as conduziu à soteriologia budista. E, por fim, na terceira e última parte, colocar em diálogo os conceitos de teopoética e erotismo, conforme formulados por Georges Bataille (2017) e Octavio Paz (1994), com a interpretação na literatura do Therīgāthā.

\section{A VOZ DAS PRIMEIRAS MULHERES NA LITERATURA BUDISTA}

A história das primeiras mulheres budistas foi contada através do Therīgāthā (Canções das Anciãs), que são as vozes das primeiras monjas do budismo, uma literatura em versos que registraram como foi a vida dessas mulheres, suas inquietudes, lutas e vitórias. Nona Olivia, pesquisadora de mulheres anciãs na religião, diz que, para ler o Therīgāthā, é necessário entender o contexto cultural e histórico de vida dessas mulheres que viviam na Índia antiga, se distanciado daquilo que muitos/ as referem como o feminino, um termo quase Jungiano, popularizado no começo da segunda onda do feminismo.

No entanto, as mulheres, como muitas mulheres de outras raças ou de ascendência não europeia salientaram, a noção de um "feminino" essencial ingenuamente assume as normas culturais, raciais e de classe que excluem as vozes daqueles que não possuem estas qualidades culturalmente idealizadas. Não há um "feminino" universal. [...] Sugiro que não leiamos o Therīgāthā primeiramente como um relato histórico da vida dessas mulheres do $6^{\circ}$ século a.C.; não é a sua feminilidade que essas mulheres antigas querem enfatizar em seus poemas. $O$ ponto de sua prática buddhista não era o de reificar

3 A palavra Therīgāthā é composta da união de duas palavras. Therī significa anciã, monja mais velha em tempo de ordenamento. Gäthā significa versos. 
qualquer condição, mas estarem libertas do apego (Nona OLIVIA, 2011, p. 1-2).

Quando falamos da situação das mulheres no tempo da composição original do Therigätha, temos que pensar que elas tinham o status de coisa, objeto, propriedade. As práticas do casamento infantil, de queimar as viúvas vivas nas piras funerárias de seus maridos ${ }^{4}$, a poligamia, além de não lhes permitir acesso à educação, constituíam a realidade da época, costumes que perduraram por muito tempo e alguns deles, como o casamento infantil, persistem até hoje (Naresh ROUT, 2016). Esta condição atribuía um valor econômico às mulheres, sendo que o valor exclusivo atribuído a elas residia no seu papel reprodutivo e, mesmo neste papel, eram vistas como um campo, de tal forma que a colheita pertencia ao proprietário da semente (Sukumari BHATTACHARJI, 1991).

Em alguns dos versos, elas descrevem suas vidas pré-monásticas como esposas, mães, filhas, concubinas e prostitutas. Esses instantâneos nos permitem um breve olhar para o pano de fundo e o sofrimento que atraiu essas mulheres para o Dhamma (Nona OLIVIA, 2011, p. 2).

É desta situação que muitas mulheres estão fugindo. Algumas percebem a questão soteriológica budista e, por esta razão, adentram ao monasticismo. O modelo de libertação que o Therīgāthā apresenta refere às dificuldades e lutas destas mulheres na vida que elas tinham antes de se tornarem monjas (renunciantes), dificuldades essas diferentes das dos homens, e que também são descritas em literatura chamada de Theragāthā (thera: homem iluminado, gāthā: poema). As obras masculinas e femininas diferem em temática e nas descrições das superações para se tornarem iluminados e iluminadas. A principal fonte dos conflitos masculinos era a questão dos desejos sexuais pelas mulheres, o que combatiam minimizando o contato. Já para as mulheres, embora fosse cenário desejável para conquista da libertação, assim como era para o Buda e os monges, a floresta representava perigo latente de estupro

Quando uma mulher não possuía quem a cuidasse após a morte do marido, ou se este fosse o desejo do filho ou pai dela, após a morte do marido ela deveria acompanha-lo no pós vida, sendo morta queimada na fogueira fúnebre do marido. 
e de outras violências. Por isso, as mulheres viviam em comunidades isoladas, próximas das cidades, e os homens nas florestas (Kathryn BLACKSTONE, 2000).

De forma a enriquecer a leitura, o estudioso e comentador do Therīgätha, Dhammapala, inseriu notas ao texto detalhando as biografias destas monjas. São marcantes os ecos das angústias que permeavam a vida das mulheres. Algumas fugiram de relacionamentos abusivos, algumas lidavam com perdas, algumas consideradas "bem casadas" convenciam seus maridos a permitir que elas renunciassem a vida em família e se tornassem monjas. Quando falamos das perdas chama atenção um destes relatos, em que uma mulher perde o filho. Dentro das características da Índia daquele tempo, o sofrimento materno de gestar uma vida e depois vê-la se esvair, era uma sentença completa. Em primeiro lugar porque a mulher falhava em ser capaz de transmitir o atman (essência divina) e, em segundo lugar, implicava numa velhice de abandono. O abandono era notório porque uma mulher não possuía autonomia: na infância ela era subordinada ao pai, depois ela era subordinada ao marido e, caso ficasse viúva e não tivesse sido queimada na pira do marido, ficaria sob a responsabilidade do filho mais velho. A ausência deste filho, que necessariamente deveria ser homem, a condenava a uma situação de miserabilidade (Sharmila REGE, 2013).

A questão da situação das mulheres ao longo da história merece debate. Pode-se dizer que o apagamento das mulheres é um fato antigo, o texto do Theri-apadāna ${ }^{5}$ (composto em 273 a.C. a 232 a.C.) já mostrava uma realidade muito diferente experimentada pelas monjas frente a sociedade. No período após o império do rei Aśoka, de grande disseminação do budismo na Índia, no séc. II d.C., as memórias das mulheres foram sendo deixadas de lado pelas tradições (Nirvana FRANÇA, 2020).

Na discussão feminista budista, a transição da história para a análise e reconstrução envolve a passagem para um território quase completamente inexplorado, extremamente doloroso e estimulante. Embora tenha havido pouca ou nenhuma cultura histórica feminista

O Theri-apadana é uma hagiografia das monjas, composto no reinado do rei Asoka (273 a.C. a 232 a.C) (Charles HALLISEY, 2015). 
sobre budismo, pelo menos tem havido discussões sobre a história das mulheres no budismo 6 (Rita GROSS, 1993, p. 125, tradução nossa, grifo no original).

A história das mulheres budistas descritas no Therīgāthā não é só uma herança histórica das mulheres iluminadas no budismo, mas é de fato modelo de inspiração para mulheres. Significa, diante das dificuldades vividas, poder acessar, através dos poemas, epifanias que colocam experiências de um limite da contingência do ser e que vai além dos sofrimentos, ou seja, poder vislumbrar um potencial diferente de nós mesmos sob a luz destas epifanias (Charles HALLISEY, 2015).

Estes relatos nos mostram que os corpos femininos são propícios a alcançar a libertação. Se por um lado temos poucos exemplos de muIheres a nos inspirar, temos no passado exemplos, datando da época da fundação da comunidade monástica feminina, ecoando nos dias de hoje. $\mathrm{Na}$ história do budismo houve pouco interesse em registrar o desenvolvimento feminino. Não é possível precisar quando, mas as conquistas implementadas pelo Buda foram suprimidas pelas culturas em que o budismo floresce depois, de tal forma que, nos dias atuais, das dezoito tradições monásticas originárias, três ainda persistem. Destas, somente uma possui o mais elevado ordenamento feminino (Nirvana FRANÇA, 2020).

Daí deriva a importância de falar deste texto e trazê-lo para diálogo, em língua portuguesa, na qual ainda não temos uma versão deste trabalho. Porém há diversas traduções para línguas europeias, o que nos possibilita ter acesso a estes versos e, como mulheres, buscarmos inspiração neles. Mas porque as mulheres precisam de inspiração? "As feministas começaram a explorar o budismo porque viram possibilidades na meditação budista para o tipo de 'autocuidado' que sentiam ser um dos talentos que as mulheres deveriam cultivar entre si"' (Charles

6 In Buddhist feminist discussion, the transition from history into analysis and reconstruction involves moving into almost completely uncharted territory, which is both extremely painful and quite exhilarating. Though there has been little, if any, previous feminist historical scholarship on Buddhism, at least there have been discussions of the history of women in Buddhism.

7 Womanists had begun to explore Buddhism because they saw possibilities in Buddhist meditation for the sort of "self-care" they felt was one of the talents Womanists need to cultivate among themselves 
HALLISEY, 2012, p. 75, tradução nossa). E, por meditação não entendemos apenas o estar no presente ou praticar técnicas respiratórias, mas uma meditação capaz de transformar a realidade, uma meditação analítica e, neste sentido, faz-se necessário um arcabouço teórico, no qual os poemas do Therīgāthā se encaixam perfeitamente.

Os estudos budistas, à sua maneira, passaram a ver a vida de homens e mulheres budistas específicos como evidência a ser usada em nossos estudos, mas talvez com menos frequência vimos recursos para nossa própria reflexão sobre nós mesmos nessas vidas ${ }^{8}$ (Charles HALLISEY, 2012, p. 80, tradução nossa).

Esta inspiração que é buscada ao ler estes poemas, se deve ao fato de que podemos verificar que algumas das experiências vividas naquela época, são parecidas com a que vivemos no presente. Eles relatam formas de opressão, ausência de liberdade, dificuldades da vida, sofrimentos experenciados - seja do adoecimento, do envelhecimento, da morte de entes queridos. Lendo estes poemas podemos verificar que, da mesma forma que essas mulheres superaram e alcançaram o mais elevado fruto do caminho, nós também somos capazes de alcançá-lo.

Chamamos de canônicos os textos que a tradição incorpora dentro de seu cânone e reconhece como significativos, mas o que isso significa?

$\mathrm{Na}$ erudição moderna, tem havido uma tendência de questionar o uso da denominação "Escrituras" (implicando em um sentido de "sagrado") para textos canônicos de várias religiões do sul da Ásia. Talvez isso tenha muito em comum com a longa tradição de debate sobre a questão das escrituras / tradição versus autonomia da razão humana que foi empreendida por expoentes de diferentes religióes indianas ${ }^{9}$ (Krishna SHRIMALI, p. 16, tradução nossa).

8 Buddhist Studies has, in its own way, come to see the lives of particular Buddhist men and women as evidence to be used in our studies, but perhaps less often have we seen resources for our own reflection about ourselves in these lives.

9 In modern day scholarship, there has been a trend to question the use of appellation 'Scriptures' (implying a sense of 'the Sacred') for canonical texts of various South Asian religions. Perhaps, this has much in common with the long tradition of debate on the issue of scriptures/tradition versus autonomy of human reason that was undertaken by exponents of different Indian religions. 
Mas como podemos entender estes textos? Como podemos analisá-los nas modernas metodologias e como podemos compreender estes textos? Estas são reflexões que não se calam e que nos inquietam na leitura. Podemos ler um texto canônico como poesia, e assim sendo ela teria a capacidade de nos tocar em nossa intimidade, ou só podemos entendê-los como clássicos acadêmicos de estudos? São respostas que nos inquietam e que iremos explorar mais adiante.

\section{EU LÍRICO NA EXPERIÊNCIA FEMININA PARA O DESPERTAR}

Antes de nos questionarmos a respeito do eu-lírico no Therīgāthā, temos de nos perguntar o que é um eu-lírico. Buscando por esta resposta, ao citar Otávio Paz, Viviana Bosi diz que ele:

[...] igualmente realça a dupla condição do sujeito lírico, entre a possessão por uma alteridade e a construção pelo trabalho com a linguagem, quando sua voz se enlaça à de outros homens, e ele deixa de ser mero eu para tornar-se um "pronome inominado". Esse sujeito é composto por uma "outridade constitutiva", pois o mundo não está mais fora nem dentro, uma vez que as palavras circundam o poeta e são o seu próprio ser. Paz enfatiza a concepção do poeta como "fora de si", quando ele se torna esse "pronome original" (Viviana BOSI, 2013, p. 102).

A poetiza, no caso do Therīgāthā, transborda nos versos de sua epifania de despertar, mostrando o percurso trilhado como um caminho de pedras marcadas, indicando a rota para outras. Inspirar as futuras gerações é justamente a função destes poemas. Mas como esse eu-lírico se manifesta? Na literatura do Therīgāthā, ele se descreve a partir da experiência das mulheres em busca do despertar, uma saída do sofrimento-separação. Segundo a teologia budista, os seres nascem no saṃsāra ${ }^{10}$ e, por isso, estão sujeitos a quatro sofrimentos: adoecimento, envelhecimento, morte e reencarnação - esses são estados de sofrimento. A vida das monjas budistas celibatárias traz uma experiência de ascese, apresentada em poesia que inspira até os dias atuais os/as praticantes budistas, homens e mulheres:

10 saṃsāra em sânscrito ou em páli significa "vagando", no budismo este vagar significa manter o ciclo repetitivo de renascimentos descontrolados e condicionados pelas distorções aflitivas. 
O Therīgāthā fornece um instantâneo nas vidas dessas monjas antigas e fala sobre sua devoção à prática. Suas histórias de libertação podem ser inspiradoras para nós nos dias de hoje, tanto para leigos como ordenados, tanto para homens como para mulheres (Nona OLIVIA, 2011, p. 7).

Para ilustrar estas questões, vamos conhecer alguns dos poemas do Therīgāthā, O primeiro poema que trazemos nessa exposição do Therīgāthā é de Uttamā:

Quatro a cada cinco vezes em que eu saía do meu quarto, eu não tinha obtido a paz mental. Eu não tinha nenhum controle sobre a minha mente. Eu fui a uma monja em quem eu confiava. Ela me ensinou o Dhamma, os agregados, as seis bases dos sentidos e os elementos (khandhāyatanadhātuyo). Eu ouvi seus ensinamentos e, em seguida, sentei com as pernas cruzadas por sete dias, entregues à alegria e felicidade. No oitavo dia estiquei meus pés, tendo penetrado a ilusão do eu (tamokkhandha padāliyā) (Nona OLIVIA, 2013, p. 3, grifo no original).

Nona Olivia (2013) destaca que Uttamā se tornou monja por ter ouvido, ainda quando adolescente, os ensinamentos de uma monja sênior chamada Patacara. Através desses ensinamentos ela se inspirou a renunciar à sua vida abastada e a ordenar-se na comunidade do Buda. Sua ascese, inspirada pelos ensinamentos de Patacara, mulher em quem ela confiava, a fez alcançar a libertação. Pelo entendimento dos fatores, "os agregados, as seis bases dos sentidos e os elementos", pela fé, ela se motivou - "Eu fui a uma monja em quem eu confiava" - e com isso surgiu o desejo pela prática meditativa e pelo modo de vida conducente ao objetivo final.

O entendimento dos fatores, ou seja, dos agregados, se refere à funcionalidade do corpo, às seis bases do sentido que são órgãos sensoriais - olhos, ouvidos, nariz, língua, pele e mente, e aos elementos, que são as faculdades dos sentidos - ver, ouvir, olfato, paladar, tato e consciência (Plínio TSAI, 2018).

A primeira desta longa palavra composta utilizada por Uttamā, khandhāyatanadhātuyo, é o termo pāli khandhas, uma palavra que significa literalmente "amontoado" ou "grupo". Por todo o Therīgāthā 
lemos muitas estrofes comoventes em que as monjas se libertam após aprenderem sobre os khandas - os cinco agregados do apego (Nona OLIVIA, 2013, p. 3, grifo no original).

Uttamā expressa em seu poema a epifania do despertar, deixando de lado a projeção do eu (ilusão do eu), e compondo o que Octavio Paz (1994) chama de "outridade construtiva", conduzindo o sujeito lírico nessa construção de linguagem no imaginário. Por um lado, há o enfrentamento das dificuldades meditativas, por outro, a aplicabilidade dos ensinamentos através da compreensão que a levaram a ver a ilusão do eu.

Outro poema, intitulado "A Mãe de Sumangala", refere-se a uma mulher chamada Mutta. Ela escreve o poema para Sumangala, seu filho, que era um renunciante (monge) budista. Mutta, que antes de se tornar monja era casada, se deleita com sua liberdade nos versos, ao referir-se às suas responsabilidades domésticas renunciadas:

Querido, que é bastante livre, querido, que é completamente libertado, / Sou também bem-libertada do pilão; / meu marido sem vergonha, até trabalha embaixo da sombra, / e o meu pote que fede como uma cobra d'água me dá nojo.

Tendo destruído a raiva e o apego pelo sexo, / Lembrei-me do som do bambu sendo cortado, / Vou ao pé de uma árvore e penso: "Ah, felicidade", / e dentro da felicidade, começo a meditar"11 (Charles HALLISSEY, 2015, p. 21, traduçao nossa)

Em sua tradução do Therīgāthā, Charles Hallisey (2015) acompanha os poemas e as histórias de vida das monjas. Na história da supracitada

\footnotetext{
1 Sumangala's Mother - Addressing her son

Dear one who is quite free, dear one who is quite freed, I too am well-freed from the pestle;

my shameless husband, even the sunshade he worked under, and my pot that stinks like a water snake all disgust me.

[...]

As I destroyed anger and the passion for sex, I was reminded of the sound of bamboo being split, I go to the foot of a tree and think, "Ah, happiness," and from within that happiness, I begin to meditade.
} 
Mutta, é dito que: se, em meditação, sua mente divagava, ela recitava o poema para restaurar sua concentração. Ela repetiu o verso novamente quando foi iluminada. Era de família pobre, seus pais a casaram quando alcançou a puberdade, mas é dito que seu marido lhe deu permissão para tornar-se monja. Ela usou esses versos em suas próprias práticas espirituais e os repetiu até alcançar a paz definitiva.

Em leitura livre pode-se observar, nos versos, que o estado de sofrimento a colocou no estado de separação com aquilo que era indesejado, não só das obrigações sexuais quando se refere ao trecho "Sou também bem-libertada do pilão" - o pilão se referindo ao pênis -, como também no estado de paz de ter se libertado dos processos internos de raiva e de apego, quando se refere ao trecho "Tendo destruído a raiva e o apego pelo sexo". Outros pontos também podem ser explorados no trecho "meu pote que fede como uma cobra d'água me dá nojo", que faz uma referência ao corpo humano. Esse corpo, que cultivamos como belo e agradável, precisa ser banhado com frequência porque os fluidos corporais que possuímos são pútridos de odor desagradável, ao ponto que usamos cosméticos para dar um aroma agradável ao mesmo.

Muitos dos poemas compartilham uma visão da verdadeira natureza do corpo, combatendo sua atratividade ilusória e, por consequência, da sexualidade e sua natureza impermanente. No budismo, a sexualidade pode ser entendida de muitas formas, mas, neste contexto, é analisada como experiência do nível sensorial, pois se observa seu caráter transitório e insatisfatório.

Por outro lado, temos a questão da beleza, e novamente dobra-se a transitoriedade do corpo, o envelhecimento leva a tonicidade, o brilho e a maciez da pele. Os belos traços são substituídos por rugas e, por conta disso, tentamos frear o envelhecimento com cremes e tratamentos. Isso não era diferente no tempo da escrita destes versos.

No poema Vimala ${ }^{12}$, a própria se descreve como uma prostituta

12 Vimala was the daughter of a woman who made her living from her beauty, and Vimala did the same. One day she saw one of the Buddha's chief disciples, Moggallana, collecting alms and she tried to seduce him. Sometimes it is said that she was prompted to do this by members of an ascetic group that was a rival of the Buddha's community. In response to her efforts at seduction, Moggallana spoke some verses to her about the foulness of the body (Charles HALLISEY, 2015, p. 257). 
antes da renúncia e de se tornar monja, tendo percebido, então, que a atratividade do corpo e da beleza é ilusória e enganadora, conforme apresentado no Therïgāthà versos 72-74:

Intoxicada pela minha (boa) pele, minha aparência, beleza e fama, arrogante por causa da minha juventude, eu desprezava outras mulheres.

Tendo decorado este corpo, muito tolo e enganador, eu estava na porta do bordel, como uma caçadora estendendo uma armadilha, mostrando minha ornamentação. Muitos segredos (lugares) foram revelados. Eu fiz vários tipos de conjuração, rindo de muitas pessoas ${ }^{13}$ (Kathryn BLACKSTONE, 2000, p. 3, tradução nossa).

De acordo com Kathryn Blackstone, (2000), este poema se refere à plena consciência de que os prazeres são construções mentais. Ao se referir aos tolos, ela reconhece, também, o que seu corpo representa aos outros é sofrimento, uma aparência suficiente para desejá-la, comparando seu corpo à armadilha de um caçador. Na tradução de Charles Hallisey (2015), a descrição da história de Vimala diz que ela tentava seduzir o monge Mogallana, um dos principais alunos do Buda. Em resposta ao seu esforço de sedução, ele recitou para ela um verso sobre a sujeira do corpo. Após refletir sobre impermanência do corpo e da beleza, Vimala gerou fé nos ensinamentos que ali recebera, se tornando uma renunciante (monja). Seus versos no Therīgāthā mostram como sua experiência e investigação a levou à iluminação (despertar), por acessar os estados de sofrimento nas relações - ao observar o sofrimento dos outros, referindo-se aos homens que a desejavam, a impermanência da própria beleza e a compaixão - quando se refere a competição com as outras mulheres no bordel.

Desta forma, podemos perceber que o eu-lírico, na experiência feminina nos poemas do Therīgāthā, nos mostra como a expressão poética as conduziu essas mulheres à soteriologia budista. Charles Hallisey (2015)

13 Intoxicated by my (good) complexion, my figure, beauty, and fame, haughty because of my youth, I despised other women. Having decorated this body, very variegated, deceiving fools, I stood at the brothel door, like a hunter having spread out a snare, showing my ornamentation. Many a secret (place) was revealed. I did various sorts of conjuring, laughing at many people (Therīgāthā 72-74). 
diz que os poemas do Therīgāthā são sobre esta soteriologia (libertação), enunciados de inspiração sobre a alegria de estar livre e de ser fonte de inspiração a quem os lê, com o objetivo proposto nos ensinamentos do Buda histórico: a libertação dos sofrimentos, a paz definitiva.

\section{EROTISMO NA TEOPOÉTICA: POSSIBILIDADES DE DIÁLOGO NA LITERATURA DO THERİGĀTHĀ}

O estudo teopoético tem seu embrião nas décadas de 1950 e 1960 no Concílio Vaticano II para trazer a importância de artistas exercerem suas atividades com autonomia. O marco foi um número da revista Concilium, publicado na década de 1970, que tinha como ênfase as relações entre teologia e literatura. A teopoética, em termos gerais, refere-se a pensar o discurso do sagrado na literatura (Márcio CAPELLI, 2020). Ainda o termo teopoética em si seja cunhado posteriormente, notamos um progressivo interesse neste campo. "O testemunho poético nos revela outro mundo dentro deste, o mundo outro que é este mundo. Os sentidos sem perder seus poderes, convertem-se em servidores da imaginação e nos fazem ouvir o inaudito e ver o imperceptível" (Octavio PAZ, 1994, p. 11). Com este olhar, saboreamos as palavras da poesia, podendo revisitar tempos que, embora remotos, seguem vivos em nosso imaginário e tocam nossos corações de maneira que somos transportados para aquele momento e lugar.

A humanidade nunca pôde buscar aquilo que a religião busca desde sempre, a não ser num mundo onde sua busca dependia de causas duvidosas, submetidas, senão ao movimento de desejos materiais, a paixões de circunstância: ela podia combater esses desejos e essas paixões, podia também servi-los, mas não podia lhes ser indiferente. (Georges BATAILLE, 2017, p. 57).

Neste sentido, Octavio Paz (2012) faz uma crítica em relação ao sagrado como colocado na inspiração poética. Ele argumenta que a inspiração não vem somente de uma experiência religiosa, como também não vem somente do poeta e da poetisa, mas que pode vir também de outro, pois através do outro podemos expressar aquilo que somos. Desta forma, é possível encontrar em nós aquilo que não somos, sendo um meio termo da experiência religiosa. 
A relação entre erotismo e poesia é tal que se pode dizer, sem afetação, que o primeiro é uma poética corporal e a segunda uma erótica verbal. Ambos são feitos de uma oposição complementar. A linguagem - som que emite sentido, traço material que denota idéias corpóreas - é capaz de dar nome ao mais fugaz e evanescente: a sensação; por sua vez, o erotismo não é mera sexualidade animal - é cerimônia, representação. $O$ erotismo é sexualidade transfigurada: metáfora. A imaginação é o agente que move o ato erótico e o poético (Octavio PAZ, 1994, p. 12).

Por isso, a expressão da teopoética exposta pelas monjas no Therīgāthā, se aproxima com a inspiração em suas vivências, no ser-relação, uma abertura para vivenciar aquilo que não tinham e desejavam ser e ter: a paz e a liberdade na vida de renúncia abriam possibilidades de transcender o que não eram antes de se tornarem monjas. No próprio discurso expresso em seus poemas, que as faziam conscientes de si mesmas, elas forneciam imagens, relatos, descobertas - um ir além, para um limite de contingência para além dos sofrimentos vivenciados. Muitas vezes, as palavras escolhidas nos remetem a metáforas de suas vidas antes do ordenamento, fatos que fundamentam e são a base do desenvolvimento de renúncia dessas mulheres, colocando o erótico como pauta em alguns dos poemas, como poderemos conhecer mais adiante. De qualquer forma,

[...] tratando-se de erotismo (ou de religião em geral), sua experiência interior lúcida era impossível num tempo em que não despontava claramente o jogo de equilíbrio do interdito e da transgressão, que ordena a possibilidade de ambos. Mas é insuficiente saber que esse jogo existe. $O$ conhecimento do erotismo, ou da religião, exige uma experiência pessoal, igual e contraditória, do interdito e da transgressão. (Georges BATAILLE, 2017, p. 59).

Estas experiências pessoais fazem parte dos mais de setenta relatos do Therigāthā, compondo seus mais de quinhentos versos, dos quais trazemos como exemplo o poema de Nanduttara ${ }^{14}$, que expressa

14 Nanduttara nasceu numa família Brahmânica. Ela se tornou primeiramente uma Janista, e como Bhadda Kundalakesa, ela perambulou pela Índia em busca de pessoas que gostariam de deba- 
a inspiração de suas vivências para uma abertura além das amarras do sofrimento do corpo:

Honrei o fogo, a lua e o sol, e os deuses, / No vau do rio, eu fui para dentro d'água.

Tomando vários votos, raspei metade da minha cabeça, / Fiz uma cama no chão, não desfrutei da refeição à noite.

Irritada como eu estava por conta do impulso pelo sexo, / Eu faria um favor para este corpo / Com banhos e massagens, / E deliciada em joias e enfeites.

Então confiante, me tornei uma renunciante. / Uma vez visto como o meu corpo era, não há mais impulso pelo sexo.

Todas as existências foram cortadas, desejos e aspirações também, / Cada amarra desamarrada, alcancei a paz da mente ${ }^{15}$ (Charles HALLISEY, 2015, p. 57, tradução nossa).

De acordo com Kathryn Blackstone (2000), o poema de Nanduttara refere-se a suas atividades religiosas anteriores à conversão ao budismo, como "ministrar ao corpo" a sexualidade para ver o sofrimento do corpo e sua transitoriedade. Sua conversão - e subsequente libertação - é o resultado de "ver o corpo como realmente era". Neste sentido, em leitura livre do poema, pode-se interpretar que a conversão se refere à renúncia (renunciante - monja), ou seja, ao impulso que a fez tomar os votos celibatários; a iluminação - o processo de libertar-se das amarras, expresso em "cada amarra desamarrada". Tal impulso a colocou em contato com a paz através de um limite de contingência de paz absoluta:

ter tópicos religiosos com ela. Um dos debates foi com um dos dois discípulos principais do Buddha, Moggallana. Ele a derrotou em debate, e ela se converteu ao Budismo. Ela se tornou iluminada rapidamente após ter adentrado na comunidade de monjas budistas. Ela disse estes versos no tempo da sua iluminação. (Charles HALLISEY, 2015, p. 250, tradução nossa).

15 I honored fire, the moon and sun, and gods, at the ford in the river, I went down into the water. I Undertaking many vows, I shaved half my head, I made a bed on the ground, I didn't enjoy food at night. / Vexed as I was by the urge for sex, I would do this body a favor with baths and massages, and delight in jewelry and finery. I Then confident, I went forth to homelessness. Once I saw the body as it was, the urge for sex was no more. / All existences are cut off, wants and aspirations too, every tie untied, I have attained peace of mind. 
O conhecimento é a ponte da aquisição das características do real-absoluto, pois por meio dele, o intelecto se torna o real-absoluto. Esse conhecimento vai se expandindo cada vez mais e tomando o lugar da natureza distorcida em todos os agregados, transformando-os na natureza do real-absoluto. $O$ resultado da expansão completa desse conhecimento é a paz definitiva (Plínio TSAI, 2018, p. 43).

Georges Bataille (2017), na obra "O Erotismo", disserta sobre o erotismo do sagrado, que trata da experiência interior como sendo uma experiência do inefável ou real-absoluto. Também na definição do erotismo dos corpos a dissolução relativa com a sexualidade traz a descontinuidade do ser. Em uma leitura e diálogo com o poema de Nanduttara: "Uma vez visto como o meu corpo era, não há mais impulso pelo sexo. Todas as existências foram cortadas, desejos e aspirações também", a descontinuidade se dá a partir do erotismo com o desejo sexual. A experiência sexual anterior permitiu uma experiência com o inefável ou real-absoluto: "alcancei a paz definitiva".

Outro diálogo no Therīgāthā é através da história de Ambapali, que antes da vida de renunciante era uma prostituta. É um poema de dezenove versos que traz a meditação sobre a impermanência, usando o corpo, sendo Ambapali uma cortesã que ficou muito conhecida na literatura budista por sua beleza. Kathryn Blackstone (2000) coloca que Ambapali via a doutrina budista como espelho, no qual ela enxergava a verdade da impermanência refletida em sua própria experiência de envelhecimento no corpo.

Este corpo já foi assim / agora fraco com a idade e caído de seu orgulho, / é o lar de muitos sofrimentos / como uma casa velha, com as paredes caindo.

É como o Buda, aquele que falou da verdade, disse, / nada diferente disso $^{16}$ (Charles HALLISEY, 2015, p. 141, tradução nossa).

Charles Hallisey faz considerações ao poema de Ambapali dizendo que o poema traz o tema central do Budismo: ensinamentos sobre a

${ }_{16}[\ldots]$ This body was once like that, / now feeble with age and fallen from its pride, / it is the home of many sufferings, / like an old house, the plaster falling down. It's just as the Buddha, the speaker of truth, said, / nothing different than that. 
impermanência - "tudo é impermanente, pois tudo neste mundo falta existência inerente”. Ele diz que apesar do poema não ser um texto central de meditação, não se pode reduzi-lo sem considerar o entendimento budista que ele contém, "a própria vida do verso". Uma das questões fundamentais do autor é a consciência da morte, que no poema de Ambapali, é o próprio decaimento do corpo.

Em diálogo com Georges Bataille (2017), "a própria vida do verso" remete ao que ele chama de "experiência interior", ou seja, a investigação da própria realidade até alcançar algo que está além da linguagem. Aquilo expresso como um limite de contingência em Bataille, pode ser entendido como o inefável para o budismo.

Octavio Paz (2012) diz sobre o que une a poesia, religião e erotismo é a unidade e fusão que acontece pela via da "outra margem", o retirar-se de si como experiência para encontrar-se consigo mesmo/a, sendo a poesia revelação da nossa condição:

Aquele que está realmente a sós consigo mesmo, aquele que se basta em sua própria solidão, não está sozinho. A verdadeira solidão consiste em estar separado do seu ser, em ser dois. [...] Seremos o seu vazio, o rastro da sua ausência? É uma imagem? Mas não é o espelho, mas sim o tempo que se multiplica. [...] Há um vazio, uma fossa aos pés (Otávio PAZ, 2012, p. 141).

No budismo, o que revela a nossa condição e faz o salto "para outra margem" é o conhecimento (prajña) da realidade interdependente e impermanente da nossa existência:

[...] por meio do aprendizado sobre o que é a realidade, por meio de um conhecimento (prajna) capaz de libertar do samsara, de corrigir as distorções que vem das aflições e das tendências por meio da visão de como as coisas realmente são, da realidade (yathabhutam) (Plínio TSAl, 2018, p. 44, grifos no original).

O Buda, a partir dessa investigação da realidade, descobriu que há uma natureza do inefável, que foi chamada de natureza iluminada ou completa desperta e inefável (Plínio TSAl, 2019, p.222). A outra margem faz referência a uma metáfora, onde os ciclos de renascimentos descon- 
trolados (sa? $s a \bar{r} a)$, sujeitos ao sofrimento do adoecimento, envelhecimento, morte e reencarnação, seriam como um mar revoltoso onde os seres são jogados e levados pelas fortes ondas. A outra margem seria a segurança do solo firme onde tais sofrimentos não existem mais, em Páli o nibbana (nirvana em sânscrito).

O que podemos aprender com o Therīgāthā,

[...] esses versos enfatizam o Ensinamento do Buddha no cânone pāli, e de forma extraordinariamente poderosa deixam claro que essas mulheres receberam, praticaram, se libertaram por meio deles e ensinaram os mesmos ensinamentos que recebemos hoje. [...] Independentemente do nosso gênero, podemos nos identificar com essas mulheres. (Nona OLIVIA, 2011, p. 2).

Como colocado por Nona Olivia (2011), ao reconhecer uma verdade mais profunda dos sofrimentos existenciais, homens ou mulheres compartilham das experiências sem a necessidade de normas culturais de gênero. Essas mulheres em seu tempo e suas vivências proporcionaram práticas que as levaram à libertação do sofrimento, chamada de natureza iluminada.

\section{CONSIDERAÇÕES FINAIS}

O eu-lírico nos poemas do Therīgāthā expressam não só uma possibilidade de saída dos sofrimentos das experiências de vida, tornando-se vozes para as outras - representando os sentimentos de renúncia de suas vidas, sentimentos de violência, vergonha e medo que as mulheres vivenciavam. Mas, principalmente, uma experiência poética que conduz ao sentido soteriológico budista, objetivo proposto nos ensinamentos do Buda histórico: a libertação definitiva dos sofrimentos.

A possibilidade de diálogo com o erotismo na teopoética mostra similares de alcance de uma subjetividade do ser, que está em relação com o outro e consigo mesmo. As epifanias acessadas através dos poemas colocam experiências de libertação (Charles HALLISEY, 2015).

A experiência poética no Therīgāthā nos propõe encontrar respostas para os sofrimentos existenciais e vislumbrar que é possível alcançar a 
libertação deles. O entendimento da realidade interdependente e impermanente descritos nos poemas mostram que há uma natureza do inefável, que foi chamada pelo Buda de natureza iluminada ou completa desperta e inefável (Plínio TSAI, 2019).

Assim, ecoando do passado ao nosso presente, estes poemas possuem o valor inestimável de dar esperança às mulheres, mostrando que o corpo feminino pode alcançar o maior fruto do caminho, ao contrário do que as culturas patriarcais podem querer impor. Estes versos servem para preencher a lacuna citada por Rita Gross (1993) a respeito da necessidade de exemplos femininos, mostrando que as pioneiras foram mulheres de luta, determinadas, e que alcançaram este almejado fruto espiritual. De tal forma que, se nos reconhecemos nos problemas por elas vividos, nas opressões sofridas, nos sofrimentos experenciados, nas suas experiências religiosas e de fé, podemos também crer na superação, basta termos o mesmo esforço e determinação.

\section{REFERÊNCIAS}

BATAILLE, Georges. O Erotismo. Belo Horizonte: Autêntica, 2017.

BLACKSTONE, Kathryn R. Women in footsteps of the Buddha: Strugle for liberation in the Therigata. Dheli, Motilal Banarsidass Publication, 2000.

BHATTACHARJI, Sukumari. Motherhood in Ancient India. Economic and Political Weekly, vol. 25, no. 42/43, 1990. Disponível em: < www.jstor.org/stable/4396892 >. Acesso em: 18 jan. 2019.

BOSI, Viviana. O sujeito lírico e o sujeito pedra. Rev. Bras. Psicanál., v. 47, 2013. Disponível em: < http://pepsic.bvsalud.org/scielo.php?script=sci_arttext\&pid=S0486-641X20 13000400011\&lng=pt\&nrm=iso >. Acesso em: 20 fev. 2021.

BUSWELL, Robert E.; LOPEZ, Donald S. (Eds.). The Princeton dictionary of Buddhism. Princeton: Princeton University Press, 2014.

CAPELLI, Marcio. Aula ministrada na disciplina "Teologia e Cultura", de 29 de abril de 2020. São Bernardo do Campo: Universidade Metodista de São Paulo, 2020.

FRANÇA, Nirvana de O. M. G de. Gurudharmas: Processos de construção e corrupção do cânon referente às obrigações de monjas budistas iniciantes. 16of. Dissertação (Mestrado em Ciências da Religião) - Universidade Metodista de São Paulo. São Bernardo do Campo, 2020.

GROSS, Rita M., Buddhism After Patriarchy: A Feminist History, Analysis, and Reconstruction of Buddhism. New York: State University of New York Press, 1993. 
GROSS, Rita M., Mulheres budistas como líderes e professoras. Revista de Estudos Feminista, Florianópolis, v. 13, n. 2, p. 415-423, Aug. 2005. Disponível em: < http://www. scielo.br/scielo.php?script=sci_arttext\&pid=S0104-026X2005000200015\&lng=en\&nrm=i so >. Acesso em: 03 jul. 2020.

HALLISEY, Charles THERĪGĀTHĀ: Poems of the first buddhist women. Londres: Murty Classical Library, 2015.

HALLISEY, Charles. "It Not the Only One": Womanist Resources for Reflection in Buddhist Studies in Buddhist-Christian Studies, Vol. 32, 2012. Disponível em: < https://www.jstor. org/stable/23274471 >. Acesso em: 02 fev. 2021.

OLIVIA, Nona (Sarana). Aprendendo com o Therīgāthā - O que libertou a venerável monja Uttamā. The Sati Journal, The Journal for the Sati Center Buddhist Studies. Disponível em: < https://www.sati.org/wp-content/uploads/pre-2013/Aprendendo-com-o-Therigatha.pdf >. Acesso em: 07 jul. 2020.

PAZ, Octavio. O arco e a lira. São Paulo: Cosac Naify, 2012.

PAZ, Octavio. A dupla chama: amor e erotismo. São Paulo: Siciliano, 1994.

REGE, Sharmila. Feminist critique of upanishads. Thesis. Department of Philosophy, University of Calicut, 2013. Disponível em < https://shodhganga.inflibnet.ac.in/bitstream/10603/159896/11/11\%20chapter5.pdf >. Acesso em: 12 ago. 2019.

ROUT, Naresh. Role of Women in Ancient India. Odisha Review, jan/2016. Disponível em: < magazines.odisha.gov.in/Orissareview/2016/Jan/engpdf/43-48.pdf >. Acesso em: 10 ago. 2019.

TSAI, Plínio Marcos. Comentário ao Tratado Tesouro da Realidade Inefável de Vasubandhu. Valinhos: ATG, 2018.

TSAI, Plínio Marcos. Tratado da Refutação do Personalismo. Valinhos: Editora BUDA, 2021.

TSAI, Plínio Marcos. Sermão do Grande Fundamento: - Tradução Bilíngue e Comentário. Valinhos: ATG, 2019.

Submetido em: 17-3-2021

Aceito em: 14-5-2021 